\title{
Four new cyclic peroxides from the Marine Sponge Plakortis simplex
}

\author{
Buyng Su Hwang and Jung-Rae Rho*
}

Department of Oceanography, Kunsan National University, Jeonbuk 573-701, Korea

Received June 4, 2013; Revised June 07, 2013; Accepted June 10, 2013

\begin{abstract}
Four new cyclic peroxide compounds (1 $\sim 4)$ were isolated from the marine sponge Plakortis simplex. Their structures including relative stereochemistry were determined by MS and NMR analysis. All compounds, a side carbon chain with 10 carbons, were very unstable. After transformation into methyl ester analogues, the structure determination was conducted. Compounds $1 \mathrm{a}$ and $2 \mathrm{a}$ are stereoisomers, assigned as $3 S^{*}, 4 S^{*}, 6 R^{*}$ and $3 R^{*}$, $4 S^{*}, 6 R^{*}$, respectively. Similarly, compounds 3 a and $4 \mathrm{a}$, replaced the methoxy group with an aliphatic methyl, are also stereoisomers. Compounds 1a and 2a exhibited the strong antifungal effect against the fungus Candida albicans.
\end{abstract}

Keywords 1D and 2D NMR, Plakortis simplex, stereoisomer, cyclic peroxide, antifungal activity

\section{Introduction}

Sponges have been the most plentiful sources of numerous biologically active and structurally novel secondary metabolites. ${ }^{1}$ As part of an ongoing search for new bioactive metabolites from the Korean sponges, four $5 a, 8 \beta$-epi-dioxy sterols including a new derivative were isolated from a sponge of Plakortis simplex collected in Keomun island, the southeast of Korea. ${ }^{2}$ More recently, fractionation for $P$. simplex extract exhibited the strong antifungal activity and led to the isolation of four new cyclic peroxide compounds $(\mathbf{1} \sim \mathbf{4})$ by the activity-guided separation. Cyclic peroxides, given as 1, 2-dioxane with an acetic acid moiety at $\mathrm{C}-3$ and an aliphatic chain at C-6, have been described from a number of marine organisms, especially from sponges of the family Plakinidae. ${ }^{3}$ After the first report of plakortin, ${ }^{4}$ an increasing number of related compounds were been characterized, including minor cyclic peroxides in which the alkyl chain terminates with a phenyl residue. ${ }^{5,6}$ Many of the peroxy compounds exhibited cytotoxicity against P-388, HT-29 tumor cells, ${ }^{7,8}$ antifungal, ${ }^{9}$ antiplasmodial activity. ${ }^{10}$ Over the last few decades, peroxide-based drugs have also been considered as one of the most remarkable advancements in malaria chemotherapy. ${ }^{11,12}$

In this paper we report the isolation of four cyclic peroxides and their structure elucidations. Unfortunately, four isolated compounds were very unstable. Therefore, the structures of four compounds were determined after transformation into methyl ester analogues. The interpretation of $1 \mathrm{D}$ and 2D NMR analysis completely led to the NMR assignments for all compounds.

\section{Experimental Methods}

General Experimental- All NMR spectra were recorded on a Varian VNMRS 500 spectrometer in $\mathrm{CDCl}_{3}$ solution. Chemical shifts of the proton and carbon spectra were reported in reference to residual solvent peaks at $7.26 \mathrm{ppm}$ and $77.0 \mathrm{ppm}$, respectively. For all experiments, the temperature was stabilized at 297K. The parameters used for 2D NMR spectra were as follows; The gradient COSY spectra were

\footnotetext{
* Address correspondence to: Jung-Rae Rho, Department of Oceanography, Kunsan National University, Jeonbuk 573-701, Korea; E-mail: jrrho@kunsan.ac.kr
} 
collected with a spectral width $2567 \mathrm{~Hz}$ in a 512 (t1) $\times 1024(\mathrm{t} 2)$ matrix applying the pulse gradient of $1 \mathrm{~ms}$ duration with a strength $10 \mathrm{G} / \mathrm{m}$ and processed with a sinebell function. The gradient HSQC spectra were measured in a $128(\mathrm{t} 1) \times 1024(\mathrm{t} 2)$ matrix with $J_{\mathrm{CH}}=$ $140 \mathrm{~Hz}$ and processed in a $256(\mathrm{t} 1) \times 1024(\mathrm{t} 2)$ matrix by a linear prediction method for a higher resolution. The gradient HMBC experiment was optimized for the long-range coupling constant of 8 Hz. The HSQC and HMBC experiments were utilized by the pulse gradients of $1 \mathrm{~ms}$ duration and $10 \mathrm{G} / \mathrm{m}$ strength to reduce the artifacts in the spectra. HPLC was carried out on a Varian equipment (Prostar 210 pump and Prostar 355 Refractive Index detector)

Collection, Extraction and Isolation- The marine sponge Plakortis simplex (sample No 08K-6) was collected by hand using SCUBA at a depth of 20-30m at Keomun island, Korea in 2008. The freeze-dried specimen was extracted with $\mathrm{MeOH}$ twice at room temperature. The crude extract was partitioned between $\mathrm{H}_{2} \mathrm{O}$ and $\mathrm{CH}_{2} \mathrm{Cl}_{2}$ solvents and then the organic layer re-partitioned between $n$-hexane and $15 \%$ aqueous $\mathrm{MeOH}$ to remove the fatty acid. The polar fraction was in turn subjected to reversed-phase vacuum flash chromatography eluting with stepwise gradients of $\mathrm{MeOH}$ in $\mathrm{H}_{2} \mathrm{O}(50 \%, 60 \%$, $70 \%, 80 \%, 90 \%$, and $100 \%$ ). Among them, the $100 \%$ $\mathrm{MeOH}$ fraction $(\mathrm{c} a 1.0 \mathrm{~g}$ ) showed a moderate antifungal effect on the fungus Candia albicans. For effective separation of active compounds, the fraction was divided into five sub-fractions (M1-M5) by using Sephadex LH20 open column chromatography. M4 fraction (130mg, $85 \sim 110 \mathrm{~min}$ ) was separated by revered-phase HPLC (YMC ODS-H80 column, 150 $\times 20 \mathrm{~mm}$, varian RI detector) using a solvent system $\left(\mathrm{H}_{2} \mathrm{O}: \mathrm{MeOH}=10: 90\right)$ to yield two mixed fractions. First was re-separated by normal phase HPLC (YMC Silica column, $250 \times 10 \mathrm{~mm}$ ) with an eluant (Hexane : Ethyl Acetate $=80: 20$ ) to yield compounds 1 (5.4mg) and 2 (4.4mg). Similarly, second was re-separated by reversed-phase HPLC (YMC ODS-A column, $250 \times 10 \mathrm{~mm}$ ) using a solvent $90 \% \mathrm{MeCN}$ to yield compounds $3(4.5 \mathrm{mg})$ and 4 (2.5mg). Unfortunately, all isolated compounds were very unstable and decomposed within 2 days. For the conversion of more stable analogues, all compounds were transformed into methyl esters.

Methylation of compounds $1 \sim 4$ - Each compound dissolved in diethyl ether $(0.2 \mathrm{ml})$ was treated with excess diazomethane at room temperature for $1 \mathrm{~h}$. After quenching the reaction with the addition of $0.5 \%$ acetic acid, methyl ester compounds were purified by normal-phase HPLC (YMC Silica column, $250 \times 10 \mathrm{~mm}$, Ethyl Acetate : Hexane $=1$ : $10,2 \mathrm{ml} / \mathrm{min}$ ) to afford the methyl ester compounds 1a, 2a, 3a and 4a at the retention time of $21,22,18$, and 19 , respectively.

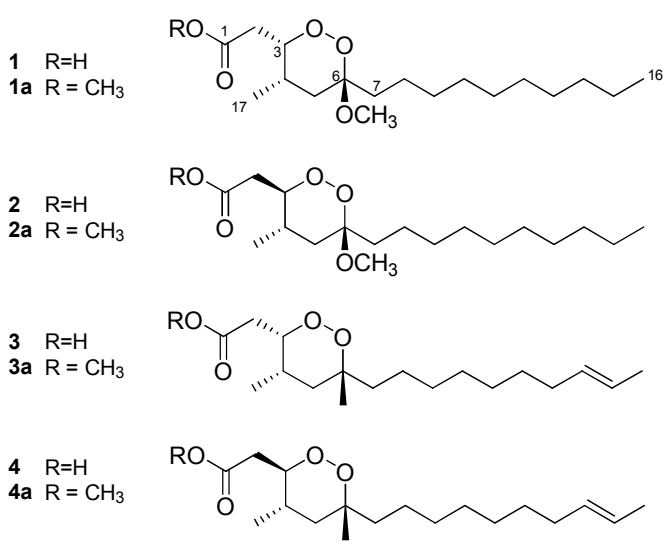

\section{Results}

Four new cyclic peroxide compounds $\mathbf{1} \sim \mathbf{4}$ were isolated from the $100 \%$ methanol fraction of $P$. simplex extract. However, all these compounds were very unstable and decomposed before the NMR experiments were accomplished. For the measurement of the $1 \mathrm{D}$ and 2D NMR data, all compounds obtained from the repeated separation were transformed into methyl ester analogues 1a $4 a$.

Compound 1a, isolated as a white amorphous solid, had the molecular formula $\mathrm{C}_{19} \mathrm{H}_{36} \mathrm{O}_{5}$ on the basis of the pseudo molecular ion $[\mathrm{M}+\mathrm{Na}]^{+}$at $m / z 367.2463$ in the HRESIMS and the ${ }^{13} \mathrm{C}$ NMR analyses, 
1a
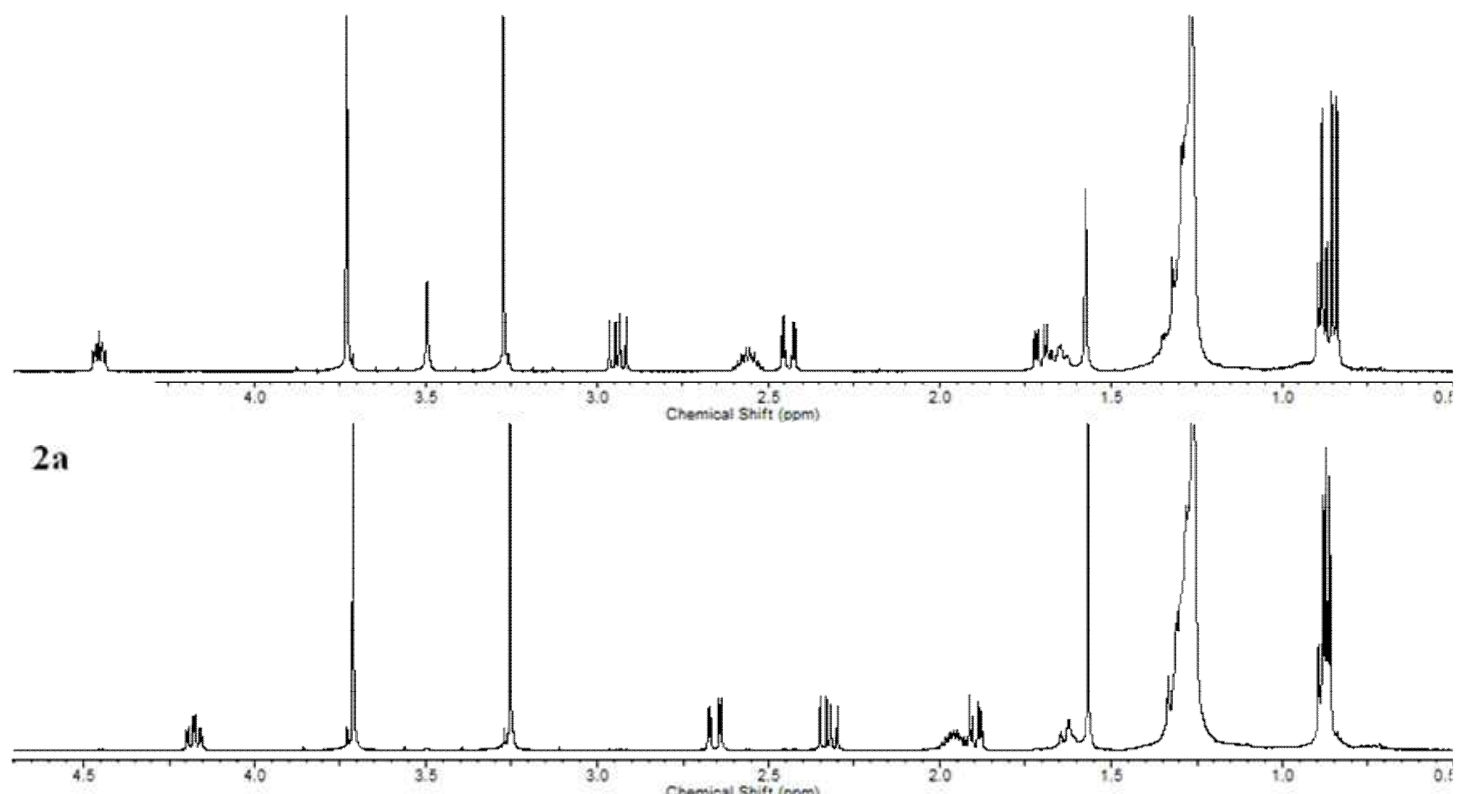

3a
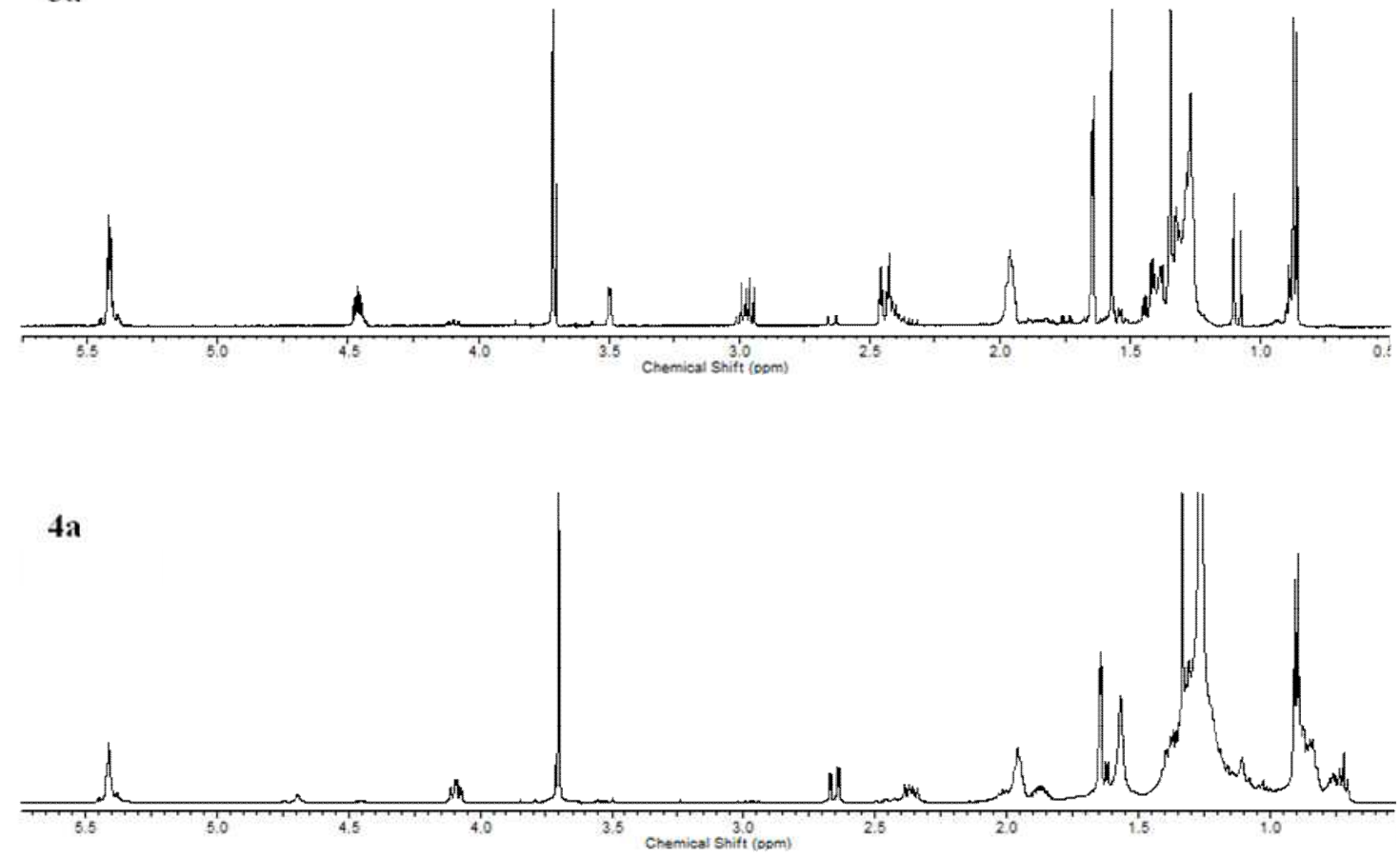

Figure 1. ${ }^{1} \mathrm{H}$ NMR spectra for compounds $1 \mathbf{1 a} \sim \mathbf{4 a}$. 
consistent with two degrees of unsaturation. The IR spectrum showed the presence of a carbonyl group from an absorption band at $1723 \mathrm{~cm}^{-1}$. The ${ }^{1} \mathrm{H}$ NMR spectrum of 1a was composed of a comparatively small number of resonances. The upfield ${ }^{1} \mathrm{H}$ NMR resonances were assigned to an aliphatic methyl doublet $(0.84, J=7.1 \mathrm{~Hz})$, a methyl triplet $(0.88, J=$ $6.9 \mathrm{~Hz}$ ) and overlapped intense methylenes corresponding to a long carbon chain [Fig. 1(a)]. In particular, the oxymethine at 4.45 and three well-resolved signals at 2.44, 2.55 and 2.93 implied that $\mathbf{1 a}$ is not a routine fatty acid with a linear carbon chain. The ${ }^{13} \mathrm{C}$ [Fig. 2(a)] and HSQC NMR spectra
A combination of 2D NMR data (COSY, HSQC and HMBC) led to define the planar structure of $\mathbf{1 a}$. Sequential COSY correlations from geminally coupled protons at ${ }_{\mathrm{C}} 2.44$ and 2.93 revealed the partial structure $-\mathrm{CH}_{2} \mathrm{CH}-(\mathrm{O})-\mathrm{CH}\left(\mathrm{CH}_{3}\right) \mathrm{CH}_{2}-$ as shown in Fig. 3. Another partial structure was also deduced as a long linear carbon chain from the COSY correlations. Each partial structure was then connected to the C-6 quaternary carbon at $\delta_{\mathrm{C}} 103.1$, which is evidenced by its long range coupling with protons in the terminal of two partial structures. Further HMBC correlations placed one methoxy group on the C-6 carbon and the carbonyl group on
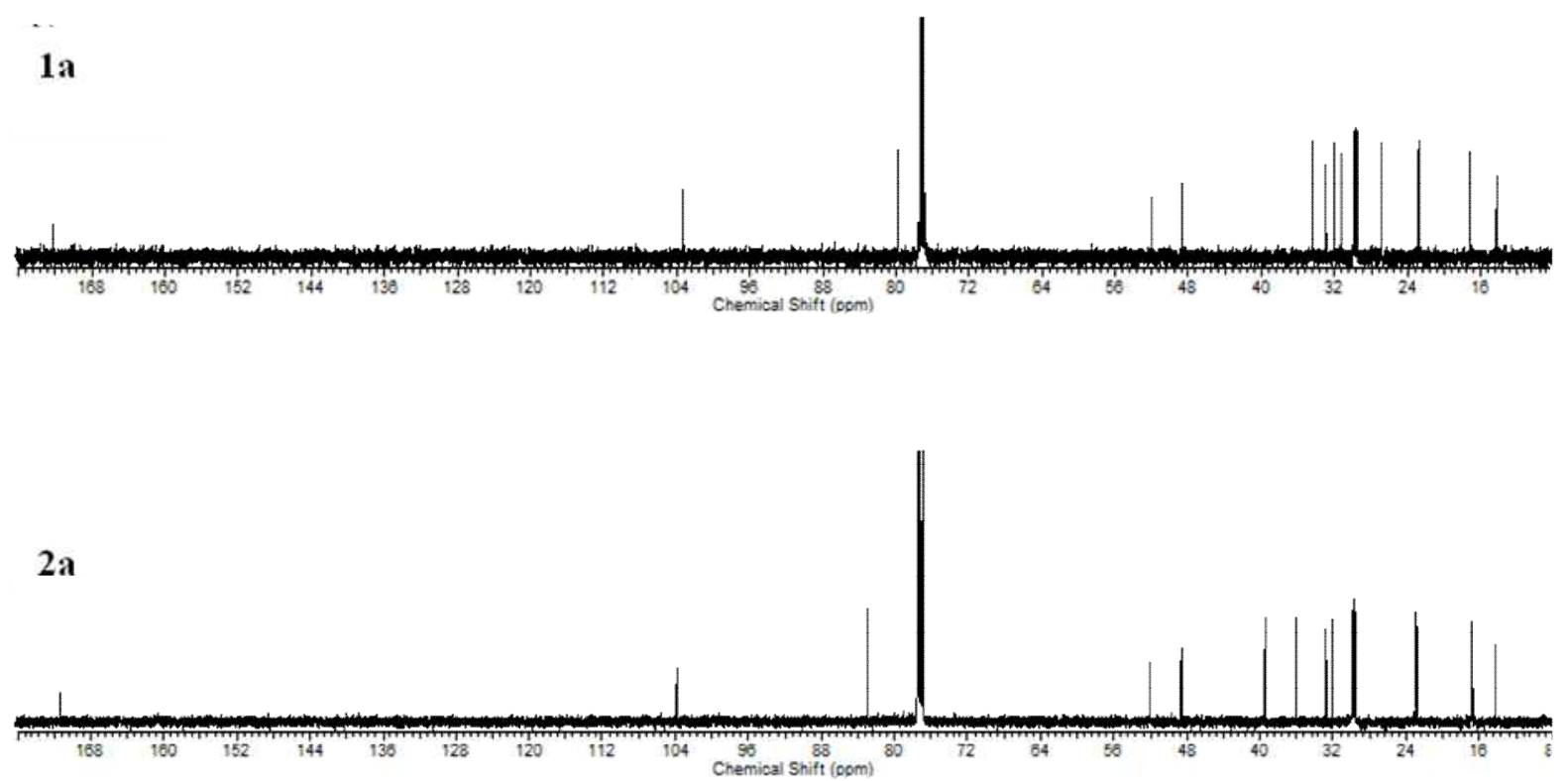

Figure 2. ${ }^{13} \mathrm{C}$ NMR spectra for compounds 1a and 2a

revealed the presence of 11 methylene and two methine carbons, together with four methyl groups. Considering the molecular formula, a characteristic quaternary signal at $\delta_{\mathrm{C}} 103.1$ was reminiscent of a ketal group. The resonances corresponding to a carbonyl and oxymethine group appeared at $\delta_{\mathrm{C}} 172.1$ and 79.5, respectively. Besides, the crowded signals in the range of $26 \sim 35 \mathrm{ppm}$ were indicative of long chain carbons. From above information, the remaining unsaturation degree indicated the possession of a ring in compound $\mathbf{1 a}$.
C-1. Similarly, another methoxy proton correlating with the carbonyl carbon in the HMBC spectrum formed a methyl ester group.

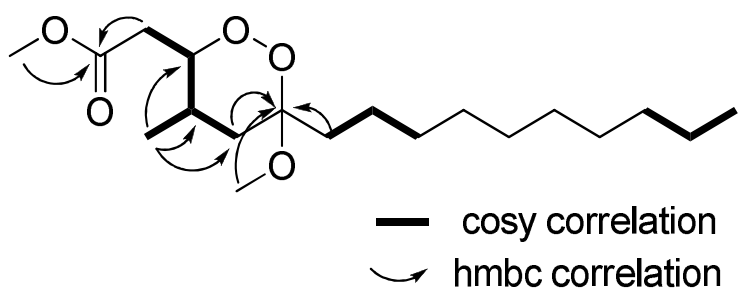

Figure 3. HMBC and COSY correlations of $1 \mathrm{a}$. 
On the other hand, the remaining two oxygen atoms and the possession of a ring of 1a allowed us to accommodate a cyclic peroxide ring by introducing a peroxide linkage between C-3 and C-6. Accordingly, 1a was determined as a cyclic peroxide with a side chain consisting of 10 carbons based on the mass analysis.

Configurational assignments of the three chiral centers in 1a were established from the proton coupling constants and the NOESY analysis. The splitting pattern of $\mathrm{H}-3$ was analyzed to have the coupling constants of 9.5, 3.7 and $3.7 \mathrm{~Hz}$ which indicate the spin coupling with one axial and two equatorial protons. From this interpretation, the H-3 oxymethine proton was suggested to be $\beta$-orientation. This configuration was also confirmed by the NOE cross peaks $\mathrm{H}-2 \mathrm{~b} / \mathrm{H}-5 \mathrm{a}$ and $\mathrm{H}-3 / \mathrm{H}-4$. Similarly, the $\beta$-orientation of $\mathrm{H}-4$ was readily determined by the obvious NOE correlation between H-2a and Me-17. Unlike above analyses, the configuration of C-6 could not be assigned by any NOE correlations. Instead, the strong NOE cross peaks between H-7 and the protons of 6-OMe enabled to the observation of the $W$ couplings from $\mathrm{H}-5$ a to the carbon at $6-\mathrm{OMe}$ and rationalized the axial position of 6-OMe group as shown in Fig. 4(a). Thus, the relative configurations of the three asymmetrical centers were assigned as $3 S^{*}, 4 S^{*}$ and $6 R^{*}$.

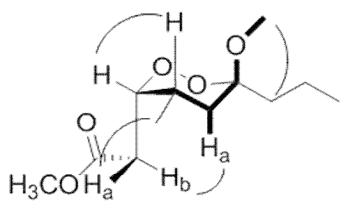

(a)

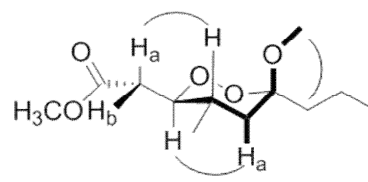

(b)
Figure 4. Stereochemistry for compounds $1 \mathrm{a}(\mathrm{a})$ and $2 \mathrm{a}(\mathrm{b})$.

Compound 2a had the same molecular formula as 1a on the basis of the mass and the ${ }^{13} \mathrm{C}$ NMR analyses, but showed the difference in the ${ }^{1} \mathrm{H}$ and ${ }^{13} \mathrm{C}$ NMR spectra [Fig. 1(b)]. The analysis of 2D NMR data suggested compound 2a to be a stereoisomer of $\mathbf{1 a}$. First of all, the H-3 oxymethine proton was shifted to the upfield and showed the coupling pattern with the coupling constants of $3.4,9.3$ and $9.3 \mathrm{~Hz}$ which represent the equatorial coupling with $\mathrm{H}-2 \mathrm{~b}$ and two axial couplings with $\mathrm{H}-2 \mathrm{a}$ and $\mathrm{H}-4$. The configuration of C-3 was also supported by the NOE cross peaks $\mathrm{H}-2 \mathrm{a} / \mathrm{H}-4$ and $\mathrm{H}-3 / \mathrm{H}-5 \mathrm{a}$ [Fig. 4(b)]. In addition, the $\beta$ - orientation of $\mathrm{H}-4$ was determined by the coupling constant, $J_{\mathrm{HH}}=13.2,4.4 \mathrm{~Hz}$, for $\mathrm{H}-5 \mathrm{~b}$. The configuration of C-6 was elucidated to be identical to that of 1a in the previous way. Therefore, the relative stereochemistry of $\mathbf{2 a}$ was assigned as $3 R^{*}, 4 S^{*}$ and $6 R^{*}$.

The molecular formula for a related compound, compound 3a, was deduced to be $\mathrm{C}_{19} \mathrm{H}_{34} \mathrm{O}_{4}$ by HRESIMS analysis. Compared with 1a, compound 3a was featured by the presence of olefinic protons, an olefinic methyl, a singlet methyl group in replacement of one methoxy [Fig. 1(c)]. A careful examination of 2D NMR spectra led to the planar structure similar to that of $\mathbf{1 a}$, but the most difference is the replacement of the 6-OMe group with a methyl group and the insertion of one double bond in the linear carbon chain. In the similar manner as 1a, the stereochemistry of $\mathbf{3 a}$ was established as $3 S^{*}, 4 S^{*}$, $6 R^{*}$ by the coupling constant and NOE analyses. In particular, the position of 6-Me was obvious in the NOESY data showing the cross peak between H-4 and 6-Me. The double bond was thought to be placed at $\mathrm{C}-14$ and $\mathrm{C}-15$ due to the olefinic methyl at $\delta_{\mathrm{H}}$ 1.64 and its geometry was assigned as $E$ form from the chemical shift value of the $\mathrm{C}-13$ allylic carbon. ${ }^{13}$ Finally, compound 4a was identified as a stereoisomer of $\mathbf{3 a}$ from the same molecular formula

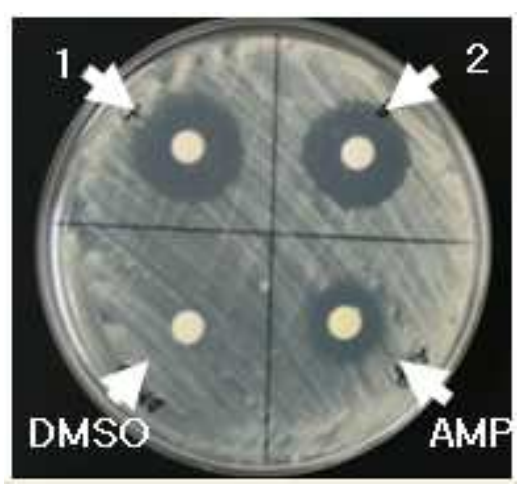

Figure 5. Antifungal test for compounds 1 and 2 with a paper disk diffusion method. 
and the different ${ }^{1} \mathrm{H}$ and ${ }^{13} \mathrm{C}$ NMR spectra. The coupling pattern of $\mathrm{H}-3$ was consistent with that of 2a and the configuration of C-3 was also confirmed by the NOE cross peaks $\mathrm{H}-3 / \mathrm{H}-5 \mathrm{a}$ and $\mathrm{H}-2 \mathrm{~b} / \mathrm{H}-4$. Except for the configuration of $\mathrm{C}-3$, the structure of compounds $\mathbf{3 a}$ and $\mathbf{4 a}$ was identical each other on the basis of the interpretation of 2D NMR spectra. The isolated compounds $\mathbf{1}$ and $\mathbf{2}$ exhibited a strong antifungal activity against the fungus Candida albicans with a paper disk diffusion method [Fig. 5]. As shown in Fig. 5, the size of inhibition zones of compounds 1 and $\mathbf{2}$ was wider than that of amphotericin(AMP) as positive control and was given as 17 and $18 \mathrm{~cm}$, respectively.

Table 1. ${ }^{1} \mathrm{H}$ NMR spectral data for compounds $\mathbf{1 a} \sim \mathbf{4 a}$ in $\mathrm{CDCl}_{3}$ recorded at $500 \mathrm{MHz}$

\begin{tabular}{|c|c|c|c|c|}
\hline no & 1a & $2 \mathbf{a}$ & $\mathbf{3 a}$ & $4 a$ \\
\hline $\begin{array}{c}2 \mathrm{a} \\
2 \mathrm{~b} \\
3 \\
4 \\
5 \mathrm{a} \\
5 \mathrm{~b} \\
7 \\
8 \\
9 \\
10 \\
11 \\
12 \\
13 \\
14 \\
15 \\
16 \\
17 \\
1-\mathrm{OMe} \\
6-\mathrm{OMe} / \\
6-\mathrm{Me}\end{array}$ & $\begin{array}{c}2.44 \mathrm{dd}(15.7,3.7) \\
2.93 \mathrm{dd}(15.7,9.5) \\
4.45 \mathrm{dt}(9.5,3.7) \\
2.55, \mathrm{~m} \\
1.28, \mathrm{~m} \\
1.70 \mathrm{dd}(13.5,4.4) \\
\mathrm{a} 1.31, \mathrm{~m} ; \mathrm{b} 1.63, \mathrm{~m} \\
1.24 \sim 1.26, \mathrm{~m} \\
1.24 \sim 1.26, \mathrm{~m} \\
1.24 \sim 1.26, \mathrm{~m} \\
1.24 \sim 1.26, \mathrm{~m} \\
1.24 \sim 1.26, \mathrm{~m} \\
1.24 \sim 1.26, \mathrm{~m} \\
1.24 \sim 1.26, \mathrm{~m} \\
1.24 \sim 1.26, \mathrm{~m} \\
0.88, \mathrm{t}(6.9) \\
0.84, \mathrm{~d}(7.1) \\
3.73, \mathrm{~s} \\
3.27, \mathrm{~s}\end{array}$ & $\begin{array}{c}2.32 \mathrm{dd}(15.9,9.3) \\
2.65 \mathrm{dd}(15.9,3.4) \\
4.17 \mathrm{dt}(3.4,9.3) \\
1.95, \mathrm{~m} \\
1.29, \mathrm{~m} \\
1.89 \mathrm{dd}(13.2,4.4) \\
\text { a } 1.29, \mathrm{~m} ; \mathrm{b} 1.62, \mathrm{~m} \\
1.24 \sim 1.26, \mathrm{~m} \\
1.24 \sim 1.26, \mathrm{~m} \\
1.24 \sim 1.26, \mathrm{~m} \\
1.24 \sim 1.26, \mathrm{~m} \\
1.24 \sim 1.26, \mathrm{~m} \\
1.24 \sim 1.26, \mathrm{~m} \\
1.24 \sim 1.26, \mathrm{~m} \\
1.24 \sim 1.26, \mathrm{~m} \\
0.88, \mathrm{t}(6.6) \\
0.86, \mathrm{~d}(7.1) \\
3.71, \mathrm{~s} \\
3.25, \mathrm{~s}\end{array}$ & $\begin{array}{c}2.43 \mathrm{dd}(15.7,4.2) \\
2.96 \mathrm{dd}(15.7,9.1) \\
4.46 \mathrm{dt}(9.1,4.2) \\
2.40, \mathrm{~m} \\
1.36, \mathrm{~m} \\
1.43 \mathrm{dd}(13.2,4.7) \\
1.38, \mathrm{~m} \\
1.29, \mathrm{~m} \\
1.26 \sim 1.31, \mathrm{~m} \\
1.26 \sim 1.31, \mathrm{~m} \\
1.26 \sim 1.31, \mathrm{~m} \\
1.26 \sim 1.31, \mathrm{~m} \\
1.95, \mathrm{~m} \\
5.41, \mathrm{~m} \\
5.41, \mathrm{~m} \\
1.64, \mathrm{dd}(1.2,3.4) \\
0.86, \mathrm{~d}(6.9) \\
3.71, \mathrm{~s} \\
1.34, \mathrm{~s}\end{array}$ & $\begin{array}{c}2.36 \mathrm{dd}(15.4,9.1) \\
2.65 \mathrm{dd}(15.4,3.4) \\
4.09 \mathrm{dt}(3.4,9.1) \\
1.87, \mathrm{~m} \\
1.33, \mathrm{~m} \\
1.62 \mathrm{dd}(13.2,4.4) \\
1.37, \mathrm{~m} \\
1.29, \mathrm{~m} \\
1.26 \sim 1.31, \mathrm{~m} \\
1.26 \sim 1.31, \mathrm{~m} \\
1.26 \sim 1.31, \mathrm{~m} \\
1.26 \sim 1.31, \mathrm{~m} \\
1.95, \mathrm{~m} \\
5.41, \mathrm{~m} \\
5.41, \mathrm{~m} \\
1.64, \mathrm{dd}(1.2,3.4) \\
0.89, \mathrm{~d}(6.6) \\
3.71, \mathrm{~s} \\
1.33, \mathrm{~s}\end{array}$ \\
\hline
\end{tabular}

Table 2. ${ }^{13} \mathrm{C}$ NMR spectral data for compounds $\mathbf{1 a} \sim \mathbf{4 a}$ in $\mathrm{CDCl}_{3}$ recorded at $125 \mathrm{MHz}$

\begin{tabular}{|c|c|c|c|c|}
\hline no & $1 \mathrm{a}$ & $2 a$ & $3 \mathbf{a}$ & $4 a$ \\
\hline $\begin{array}{c}1 \\
2 \\
3 \\
4 \\
5 \\
6 \\
7 \\
8 \\
9 \\
10 \\
11 \\
12 \\
13 \\
14 \\
15 \\
16 \\
17 \\
1-\mathrm{OMe} \\
6-\mathrm{OMe} / \\
6-\mathrm{Me}\end{array}$ & $\begin{array}{c}172.1, \mathrm{C} \\
31.1, \mathrm{CH}_{2} \\
79.5, \mathrm{CH} \\
26.8, \mathrm{CH} \\
34.2, \mathrm{CH}_{2} \\
103.1, \mathrm{C} \\
32.8, \mathrm{CH}_{2} \\
22.6 \sim 29.7, \mathrm{CH}_{2} \\
22.6 \sim 29.7, \mathrm{CH}_{2} \\
22.6 \sim 29.7, \mathrm{CH}_{2} \\
22.6 \sim 29.7, \mathrm{CH}_{2} \\
22.6 \sim 29.7, \mathrm{CH}_{2} \\
22.6 \sim 29.7, \mathrm{CH}_{2} \\
31.9, \mathrm{CH}_{2} \\
22.6, \mathrm{CH}_{2} \\
14.1, \mathrm{CH}_{3} \\
16.9, \mathrm{CH}_{3} \\
51.9, \mathrm{CH}_{3} \\
48.5, \mathrm{CH}_{3}\end{array}$ & $\begin{array}{c}171.1, \mathrm{C} \\
35.8, \mathrm{CH}_{2} \\
82.8, \mathrm{CH} \\
29.3, \mathrm{CH} \\
39.3, \mathrm{CH}_{2} \\
103.7, \mathrm{C} \\
32.6, \mathrm{CH}_{2} \\
22.6 \sim 29.8, \mathrm{CH}_{2} \\
22.6 \sim 29.8, \mathrm{CH}_{2} \\
22.6 \sim 29.8, \mathrm{CH}_{2} \\
22.6 \sim 29.8, \mathrm{CH}_{2} \\
22.6 \sim 29.8, \mathrm{CH}_{2} \\
22.6 \sim 29.8, \mathrm{CH}_{2} \\
31.9, \mathrm{CH}_{2} \\
22.6, \mathrm{CH}_{2} \\
14.1, \mathrm{CH}_{3} \\
16.6, \mathrm{CH}_{3} \\
52.0, \mathrm{CH}_{3} \\
48.5, \mathrm{CH}_{3}\end{array}$ & $\begin{array}{c}172.2, \mathrm{C} \\
31.5, \mathrm{CH}_{2} \\
79.7, \mathrm{CH} \\
27.9, \mathrm{CH} \\
36.8, \mathrm{CH}_{2} \\
80.5, \mathrm{C} \\
40.9, \mathrm{CH}_{2} \\
22.8, \mathrm{CH}_{2} \\
29.1 \sim 30.1, \mathrm{CH}_{2} \\
29.1 \sim 30.1, \mathrm{CH}_{2} \\
29.1 \sim 30.1, \mathrm{CH}_{2} \\
29.1 \sim 30.1, \mathrm{CH}_{2} \\
32.6, \mathrm{CH}_{2} \\
131.6, \mathrm{CH} \\
124.6, \mathrm{CH} \\
17.9, \mathrm{CH}_{3} \\
17.2, \mathrm{CH}_{3} \\
51.9, \mathrm{CH}_{3} \\
21.0, \mathrm{CH}_{3}\end{array}$ & $\begin{array}{c}171.1, \mathrm{C} \\
36.2, \mathrm{CH}_{2} \\
83.5, \mathrm{CH} \\
30.5, \mathrm{CH} \\
41.8, \mathrm{CH}_{2} \\
81.2, \mathrm{C} \\
40.8, \mathrm{CH}_{2} \\
23.0, \mathrm{CH}_{2} \\
29.1 \sim 30.1, \mathrm{CH}_{2} \\
29.1 \sim 30.1, \mathrm{CH}_{2} \\
29.1 \sim 30.1, \mathrm{CH}_{2} \\
29.1 \sim 30.1, \mathrm{CH}_{2} \\
32.6, \mathrm{CH}_{2} \\
131.6, \mathrm{CH} \\
124.6, \mathrm{CH} \\
17.9, \mathrm{CH}_{3} \\
17.2, \mathrm{CH}_{3} \\
51.9, \mathrm{CH}_{3} \\
20.7, \mathrm{CH}_{3}\end{array}$ \\
\hline
\end{tabular}




\section{Acknowledgement}

This work was supported by the Basic Science Program through the National Research Foundation of Korea (NRF) funded by the Ministry of Education, Science and Technology.

\section{References}

1. Blunt J. W, Copp B. R., Keyzers, R. A., Munro M. H. G., Prinsep M. R., Nat. Prod. Rep., 30, 237-323 (2013).

2. Oh J. S., Kim M. H., Song A. R., Rho J.-R., J. Korean Magn. Reson. Soc., 14, 1-8 (2010).

3. Casteel D. A., Nat. Prod. Rep., 16, 55-73 (2001).

4. Higgs M. D., Faulkner D. J., J. Org. Chem., 43 , 3454-3457 (1978).

5. Chen Y., Mccarthy P. J., Harmody D. K., Schimoler-O’Routke R., Chilson K., Selitrennikoff C., Pomponi S. A., Wright A. E., J. Nat. Prod, 65, 1509-1512 (2002).

6. Philipson D. W., Rinehart K. L. Jr, J. Am. Chem. Soc., 105, 7735-7736 (1983).

7. Rudi A., Goldberg I., Stein Z., Kashman Y., Benayahu Y., Schleyer M., Gravalos M. D. G., J. Nat. Prod., J Nat. Prod., 58, 1702-1710 (1995).

8. Cafieri F., Fattorusso E., Tagliatatela-Scafati O., Ianaro A., Tetrahedron 55, 7045-7056 (1999).

9. Gunasekera S. P., Gunasekera M., Gunawardance G. P., McCarthy P., Burres N., J. Nat. Prod., 53, 669-647 (1990).

10. Fattorusso E., Parapini S., Campagnuolo C., Basilico N., Taglialatela-Scafati O., Taramelli D., J. Antimicrob. Chemother., 50, 883-888 (2002).

11. Klayman D. L., Science, 228, 1049-1055 (1985).

12. Longo M., Zanoncelli S., Manera D., Brughera M., Colombo P., Lansen J., Mazue G., Gomes M., Talyer E. J., Olliaro P., Reprod. Toxicol., 21, 83-93 (2006).

13. Gunstone F. D., Pollard M. R., Scrimgeour C. M., Vedanayagam H. S., Chem. Phys. Lipids 18, 115-123 (1977). 